\title{
Epidemiologia e a categoria das raças: reflexões onto-epistemológicas
}

\author{
Epidemiology and the category of races: \\ onto-epistemological considerations
}

\author{
Epidemiología y la categoría de las razas: reflexiones \\ ontoepistemológicas
}

Rafael da Silveira Moreira 1,2

doi: 10.1590/0102-311X00133721

Agradeço a leitura atenta apontada nos comentários ${ }^{1}$ sobre o artigo de minha autoria ${ }^{2}$. Com efeito, a complexidade não só da temática racial, mas de todas as outras iniquidades denunciadas pelo estudo extrapolam os limites de palavras de qualquer texto. Contudo, o mundo é do tamanho daquilo que se pode ser dito sobre ele. Para este recorte, optou-se por manter a metodologia do estudo, conduzido pelo Instituto Brasileiro de Geografia e Estatística (IBGE), para falar sobre o mundo com os mesmos olhos que imediatamente apreendem o fenômeno da cor da pele, ou seja, a definição autorreferida segundo cinco categorias: indígena, amarela, parda, preta e branca.

Todas as críticas ao uso de categorias étnico-raciais são legítimas e válidas, especialmente as utilizadas pelo IBGE, que foram levantadas pelo comentário. A descrição de cada variável associada à desigualdade da distribuição dos piores sintomas, assim como as modalidades de acesso e utilização dos serviços de saúde, merecem trabalhos derivados que se ocupem com o aprofundamento dos resultados encontrados. Nesse sentido, o comentário se traduz no convite para diferentes olhares sobre o tema racial. Um trabalho não se esgota em sua publicação, mas deve provocar uma reflexão entre seus pares. Parabenizo o comentário por provocar a continuidade do debate, o que seria inesgotável em um só fôlego analítico.

A complexidade da cor da pele, raça e etnia sempre esteve presente nos estudos epidemiológicos. Kabad et al. ${ }^{3}$ realizaram uma revisão sobre o uso das variáveis raça, cor e etnia em estudos epidemiológicos sobre populações brasileiras. Em alguns estudos os indivíduos foram classificados como "pardos" em conjunto com a categoria "preta"; outros analisaram a categoria parda em conjunto com a de amarelos e indígenas; outros a denominaram como resultante da "miscigenação", entendendo-a como "mixed", "admixture" e "mixed race", ou ainda "moreno", "mulato" e "brown"; alguns a agruparam com a categoria "outros", "other" e "unknown"; os demais a excluíram das análises.

A categoria "branca" se mostrou presente em todos os estudos e o padrão geral foi aquele de ser analisada sem junção às outras categorias. Em outras palavras, para muitos estudos epidemiológicos, branco não se mistura!

Chama a atenção também a tendência maniqueísta da dualidade racial. Cerca de $40 \%$ dos estudos agruparam as categorias em duas e as analisaram como contrastantes, dispostas nas formas: "white non-white"; "white - black"; "branco - preto"; "branco - negro"; "raça negra - raça não-negra"; "black - non-black"; "negra - não-negra”; "caucasoide - negróide”; "european-brazilian - african-brazilian”;
1 Instituto Aggeu Magalhães, Fundação Oswaldo Cruz, Recife, Brasil.

2 Faculdade de Medicina, Universidade Federal de Pernambuco, Recife, Brasil.

\section{Correspondência}

R. S. Moreira Instituto Aggeu Magalhães, Fundação Oswaldo Cruz. Av. Professor Moraes Rego $s / n$, Cidade Universitária, Recife, PE 50670-420, Brasil. rafael.moreira@fiocruz.br 
"euro-descendants - afro-descendants"; "caucasian - non-caucasian”. Pode-se observar a branquitude como norma nos estudos epidemiológicos e seu contraste como um conceito negativo de cor, um desvio da norma, uma negação de sua existência, como a categoria não-branca.

O processo de identificação étnico-racial é subjetivo, já que envolve dimensões históricas, socioculturais e políticas. A própria cor do entrevistador interfere tanto no modo como classificam os entrevistados quanto como eles se classificam em termos de cor ou raça. A classificação étnico-racial também varia conforme as circunstâncias e o contexto de onde emerge. Segundo Butler 4 (p. 64), "quando se julgam as pessoas por serem quem são, estabelece invariavelmente uma distância moral clara entre quem julga e quem é julgado". Entrementes, análises que incluem as categorias raciais acabam reforçando o que chamo de "racismo epidemiológico", que ocorre quando os julgamentos clínicos se baseiam mais na cor do paciente do que na sua condição objetiva. Tais julgamentos são epidemiologicamente sustentados pelos estudos que confirmam piores condições de saúde associados às categorias raciais pardas e pretas, o que revela um viés racial implícito.

Toda forma de identificação ou rotulação racial heteronômica fere a autonomia do ato de relatar a si mesmo. A junção de pardos e pretos como negros não foi dada como opção aos entrevistados nesse ato de relatar a si mesmos. O agrupamento é válido e bem fundamentado, além de possuir força em seu engajamento e empoderamento político, mas se constitui em uma meta-classificação, ou seja, uma classificação da classificação primeira. É importante coletar e descrever fenômenos epidemiológicos na forma imediata como são apreendidos, ou seja, na forma como os indivíduos expressam sua identificação ou apresentam seus atributos.

Os agrupamentos categoriais têm finalidade analítica útil, pois corroboram os achados e as conclusões e reforçam as iniquidades, contudo, alteram a apreensão imediata do que foi apreendido. Nesse sentido, sempre que for possível apresentar os dados sem manipulação meta-classificatória e heteronômica, melhor será a exposição direta do fenômeno. Isso torna possível ao leitor a interpretação agrupada a posteriori. Já o relato agrupado em uma única categoria interdita a visibilização da proporção de pessoas que se autodeclararam pardas e pretas. Notem que é justamente o agrupamento que invisibiliza seus componentes. Um possível apagamento de indígenas pode estar ocorrendo quando eles se classificam como pardos, na fuga da perseguição colonizadora aos povos originários. Nesse sentido, o povo indígena estaria apagado duplamente, primeiramente no pardismo de seu povo e segundamente em sua junção aos pretos na constituição da população negra. Butler 4 já nos alerta sobre a violência ética no ato do reconhecimento do outro em seu relato de si mesmo. Ainda nesse escopo, o filósofo indígena Ailton Krenak 5 aponta que quando uma estatística precisa tencionar sobre como o racismo incide sobre os corpos negros de uma maneira preferencial em relação aos outros corpos, os pardos viram negros.

Diante do exposto, o problema mencionado no comentário parece recair na forma classificatória empregada segundo os critérios do IBGE. Questiona-se se devemos juntar pardo e preto em uma única categoria, a negra. Os argumentos citados apontam clara e justamente a pertinência dessa junção. Entrementes, as categorias do IBGE utilizadas reforçam as iniquidades raciais e dialogam com os outros estudos que padronizaram essa classificação com fins de comparação. A diretriz da Política Nacional de Saúde Integral da População Negra, constante na Portaria no 344/2017 do Ministério da Saúde, em seu Art. 1ㅇ, defende que "a coleta do quesito cor e o preenchimento do campo denominado raçal cor serão obrigatórios aos profissionais atuantes nos serviços de saúde, de forma a respeitar o critério de autodeclaração do usuário de saúde, dentro dos padrões utilizados pelo Instituto Brasileiro de Geografia e Estatística (IBGE) e que constam nos formulários dos sistemas de informações da saúde como branca, preta, amarela, parda ou indígena" 6 (p. 39).

Mesmo separados, pardos e pretos apresentaram as maiores chances de apresentarem piores sintomas segundo o artigo 2 . A mensuração da raça/cor buscou evitar o embranquecimento da saúde, o velamento das iniquidades, a imaterialidade nas denúncias e a suposta convivência harmoniosa entre os povos. Desmascarou uma pretendida convivência que projeta a Casa Grande e a Senzala juntas na mesa de jantar, em uma acomodação conceitual e natural da cor.

A cor parda não embranqueceu o risco dos piores sintomas e não democratizou uma justa distribuição racial dos sintomas. As diferenças não deixaram de existir em razão do não uso da categoria negra (apresentada no artigo separadamente em pardos e pretos), mas continuaram revelando desiguais condições de vida enraizadas no racismo estrutural. 
O comentário aponta questões muito importantes e problemáticas na utilização da categoria parda. Contudo, o que o estudo apontou não foi a invisibilidade da categoria negra, mas a revelação de seus componentes raciais que podem ser agrupados. Muitas vias são possíveis na escolha do percurso metodológico de qualquer trabalho científico. O que não deve ser feito é a renúncia ao debate racial pela não existência de uma pacificação classificatória da cor da pele. $\mathrm{O}$ artigo permite a leitura agrupada ou separada das categorias pardas e pretas. Embora o tema central do artigo não seja o debate racial (haja vista a necessidade de também devermos refletir sobre outras variáveis associadas a ele, como gênero), optou-se pela apresentação dos fatores associados aos sintomas da COVID-19 na forma direta como os dados foram disponibilizados. Por um lado, a inclusão de uma reflexão sobre a saúde da população negra, mesmo que incipiente, teria um ótimo acolhimento no artigo, fato lamentado pelo olhar reducionista de toda abordagem científica, incapaz de dar conta da complexidade do mundo real, necessariamente suspensa em prol da modelagem epidemiológica da sociedade. Por outro lado, a apresentação dos componentes categóricos da raça possibilita a interpretação com vários olhares, amplificando o debate para além do objetivo do estudo.

Em apertada síntese, agradeço novamente a rica oportunidade trazida pelo pertinente comentário sobre o importante aspecto da raça/cor no estudo conduzido. O debate e as pontuações colocadas, por fim, muito contribuíram para o diálogo e o preenchimento de uma importante lacuna não aprofundada no artigo.

\section{Informação adicional}

ORCID: Rafael da Silveira Moreira (0000-00030079-2901).
1. Souza J, Santos JN, Silva DFL, Silva TR. Carta às Editoras sobre o artigo de Moreira. Cad Saúde Pública 2021; 37:e00106921.

2. Moreira RS. Análises de classes latentes dos sintomas relacionados à COVID-19 no Brasil: resultados da PNAD-COVID19. Cad Saúde Pública 2021; 37:e00238420.

3. Kabad JF, Bastos JL, Santos RV. Raça, cor e etnia em estudos epidemiológicos sobre populações brasileiras: revisão sistemática na base PubMed. Physis (Rio J.) 2012; 22:895-918.

4. Butler J. Relatar a si mesmo: crítica da violência ética. Belo Horizonte: Autêntica; 2015.

5. Krenak A. O truque colonial que produz, o pardo, o mestiço e outras categorias de pobreza. https://www.youtube.com/watch?v=dvij NR9Nbgo (acessado em 28/Mai/2021).

6. Departamento de Apoio à Gestão Participativa e ao Controle Social, Secretaria de Gestão Estratégica e Participativa, Ministério da Saúde. Política Nacional de Saúde Integral da População Negra: uma política para o SUS. 3a Ed. Brasília: Editora do Ministério da Saúde; 2017.

Recebido em 28/Mai/2021

Aprovado em 03/Jun/2021 